\section{(1) \\ CrossMark}

\title{
The role of cardiopulmonary exercise tests in pulmonary arterial hypertension
}

\author{
Stefania Farina ${ }^{1}$, Michele Correale ${ }^{2}$, Noemi Bruno ${ }^{1,3}$, Stefania Paolillo ${ }^{4}$, \\ Elisabetta Salvioni ${ }^{1}$, Roberto Badagliacca ${ }^{5}$ and Piergiuseppe Agostoni ${ }^{1,6}$, on \\ behalf of the "Right and Left Heart Failure Study Group" of the Italian Society of \\ Cardiology
}

\begin{abstract}
Affiliations: ${ }^{1}$ Centro Cardiologico Monzino, IRCCS, Milan, Italy. ${ }^{2}$ Dept of Cardiology, University of Foggia, Foggia, Italy. ${ }^{3} \mathrm{AOR}$ S.Carlo, Dipartimento Cardiovascolare, Potenza, Italy. ${ }^{4}$ IRCCS SDN, Istituto di ricerca diagnostica e nucleare, Naples, Italy. ${ }^{5}$ Dipartimento di Scienze Cardiovascolari, Respiratorie, Nefrologiche, Anestesiologiche e Geriatriche, "La Sapienza” University of Rome, Rome, Italy. ${ }^{6}$ Dept of Clinical Sciences and Community Health (Cardiovascular Section), University of Milan, Milan, Italy.
\end{abstract}

Correspondence: Piergiuseppe Agostoni, Dept of Cardiovascular Sciences, Centro Cardiologico Monzino, IRCCS, via Parea 4, Milan 20138, Italy. E-mail: piergiuseppe.agostoni囚ccfm.it

@ERSpublications

CPET provides valuable information on diagnosis, prognosis and therapy in PAH but it should be performed by experts http://ow.ly/q5O230j6hta

Cite this article as: Farina S, Correale M, Bruno N, et al. The role of cardiopulmonary exercise tests in pulmonary arterial hypertension. Eur Respir Rev 2018; 27: 170134 [https://doi.org/10.1183/16000617.01342017].

ABSTRACT Despite recent advances in the therapeutic management of patients affected by pulmonary arterial hypertension (PAH), survival remains poor. Prompt identification of the disease, especially in subjects at increased risk of developing $\mathrm{PAH}$, and prognostic stratification of patients are a necessary target of clinical practice but remain challenging. Cardiopulmonary exercise test (CPET) parameters, particularly peak oxygen uptake, end-tidal carbon dioxide tension and the minute ventilation/carbon dioxide production relationship, emerged as new prognostic tools for PAH patients. Moreover, CPET provides a comprehensive pathophysiological evaluation of patients' exercise limitation and dyspnoea, which are the main and early symptoms of the disease. This review focuses on the role of CPET in the management of PAH patients, reporting guideline recommendations for CPET and discussing the pathophysiology of exercise limitation and the most recent use of CPET in the diagnosis, prognosis and therapeutic targeting of PAH.

\section{Introduction}

The cardiopulmonary exercise test (CPET) is a noninvasive method to assess functional capacity and exercise limitation, providing information about the cardiovascular, respiratory, metabolic and muscular response to physical effort. It can be recommended for all patients suffering from pulmonary hypertension $(\mathrm{PH})$ who are able to perform exercise testing and are clinically stable (New York Heart Association (NYHA) functional groups I-III). Indeed, CPET is a safe test even in patients with severe exercise limitation. As noted, it is a noninvasive method and is usually performed without assessment of arterial blood gases. However, a differential diagnosis between group 1 (pulmonary arterial hypertension (PAH)) and group 3 ( $\mathrm{PH}$ due to lung disease) might require an evaluation of changes in arterial carbon dioxide tension $\left(\mathrm{PaCO}_{2}\right)$ during exercise and in cardiac output $(\mathrm{CO})$ /oxygen uptake $\left(V^{\prime} \mathrm{O}_{2}\right)$ ratio [1]. Nowadays, CPET parameters, particularly peak $V^{\prime} \mathrm{O}_{2}$, end-tidal carbon dioxide tension $\left(\mathrm{PETCO}_{2}\right)$ and the minute

Received: Dec 132017 | Accepted after revision: Feb 192018

Provenance: Submitted article, peer reviewed.

Copyright CERS 2018. ERR articles are open access and distributed under the terms of the Creative Commons Attribution Non-Commercial Licence 4.0. 
ventilation $\left(V^{\prime} \mathrm{E}\right) /$ carbon dioxide production $\left(V^{\prime} \mathrm{CO}_{2}\right)$ relationship (measured either as its ratio at the anaerobic threshold (AT) or as its relationship slope) are considered to be of the utmost importance in the diagnosis, prognosis and therapeutic management of PAH patients. However, all CPET-derived parameters are underused even in major PH centres. This is likely due to a lack of expertise in the carrying out of CPET and because, besides haemodynamic measurements, the functional class (which is based on symptoms during exercise) and the six-minute walk test (6MWT) were historically considered enough to stratify PAH risk and predict patients' prognosis.

In this review we address the strengths and limitations of the use of CPET in PAH, focusing on pioneering use, current and previous guidelines, physiological background and CPET use in PAH diagnosis and prognosis.

\section{The CPET in PAH: from experience to guidelines}

$\mathrm{PH}$ is a progressive disease that leads to increased pulmonary arterial pressure (PAP) and pulmonary vascular resistance (PVR) as well as to loss of pulmonary vasodilator response to exercise. The main and early symptoms in $\mathrm{PH}$ are exercise intolerance and dyspnoea.

The clinical interest in $\mathrm{PH}$ is relatively recent and has developed in the last 40 years, starting after a sudden increase in PH diagnosis in Switzerland, Germany and Austria in 1967 linked to the intake of appetite-reducing drugs. The First World Symposium on Pulmonary Hypertension [2], which took place in Switzerland in 1973, proposed the first definition of primary pulmonary hypertension ( $\mathrm{PPH}$; $\mathrm{PH}$ of unknown cause) and secondary $\mathrm{PH}$ ( $\mathrm{PH}$ of known cause), focusing basically on the epidemiologic and pathophysiological features of the disease since no specific therapy was available. In the 1990s, epoprostenol was the first $\mathrm{PH}$-specific drug that was demonstrated to prolong survival and improve functional capacity, assessed as distance walked, in PPH patients [3, 4]. Therefore, starting from World Symposium on Primary Pulmonary Hypertension in Evian (1998) and carrying on during the world symposia on PH held in Venice (2003), Dana Point (2009) and Nice (2013), the guidelines were revised and the $\mathrm{PH}$ classification system improved, identifying four different categories sharing similarities in pathophysiological mechanisms, clinical presentation and therapeutic options. Indeed, a few specific therapies were approved simultaneously in the 2000s for the first group of the classification system, namely $\mathrm{PAH}[5-8]$.

The first trials mainly included patients with severe PAH and they demonstrated that haemodynamic data, functional class and the 6MWT were able to predict mortality and response to treatment [9-11]. For these reasons and thanks to the simplicity of execution for both patients and physicians, the 6MWT has been and remains until now the only exercise endpoint accepted by the Food and Drug Administration and the European Agency for the Evaluation of Medicinal Products for studies evaluating treatment effects in $\mathrm{PAH}$, even if it has been demonstrated that the change in distance walked does not correlate with survival or clinical events such as hospitalisations or need for rescue therapy [12]. Results from the STRIDE-1 trial, the first and only trial that used both 6MWT and CPET as endpoints, were also against the use of CPET-derived parameters for PAH evaluation [13]. Indeed, the study drug, sitaxentan, significantly improved the 6MWT distance but not peak $V^{\prime} \mathrm{O}_{2}$ [13]. Moreover, the 6MWT and CPET parameters were not correlated, with the lack of sufficient expertise and accepted standardisation methods in performing exercise tests in PH patients being suggested as the main reasons for this unexpected discrepancy [14]. Indeed, Oudiz et al. [14] showed that the correlation between the 6MWT and CPET measurements improved significantly as the study progressed, as did technical skills at less-experienced sites (where ability increased over time). A further important reason for discrepancy in the STRIDE study lies in considering the 6MWT unadjusted for body weight. Indeed, by taking into account patients' body size, OuDiz et al. [14] were able to show an increased correlation between 6MWT and CPET.

All these observations confirm the need for quality-controlled CPET, as reported in guidelines starting from 2009 [7]. However, in contrast to 6MWT that provides only limited clinical information, CPET has the power to reveal the underlying pathophysiological consequences of the disease process and, in recent years, several CPET variables have been recognised to be consistently altered in patients with PAH $[15,16]$. Thus, 6MWT should be considered as complementary to CPET and not a replacement for it according to the American Thoracic Society (ATS) [17]. Specifically, WenSEL et al. [18] found, in 70 patients affected by idiopathic $\mathrm{PAH}$, that systolic blood pressure at peak exercise, peak $V^{\prime} \mathrm{O}_{2}$, exercise duration, $P \mathrm{ETCO}_{2}$ at rest, $V^{\prime} \mathrm{E} / V^{\prime} \mathrm{CO}_{2}$ slope, diastolic blood pressure at peak exercise and heart rate (HR) at peak exercise predicted survival. Moreover, on multivariate analysis, peak $V^{\prime} \mathrm{O}_{2}$ and systolic blood pressure were independent predictors of survival, while haemodynamic parameters were not independently predictive of mortality.

Starting from these data, the Dana Point guidelines reported the use of peak $V^{\prime} \mathrm{O}_{2}$ as a prognostic tool in the follow-up of PAH patients, particularly younger patients who are likely able to walk more than $500 \mathrm{~m}$ 
despite the presence of severe PAH and right ventricular (RV) dysfunction [7]. In these patients, 6MWT is expected to be a submaximal test and, therefore, the additional exercise testing with CPET is particularly useful in order to obtain a more reliable assessment of functional status and RV function. In the most recent guidelines [19], a typical ventilatory pattern with low $P \mathrm{ETCO}_{2}$ and high $V^{\prime} \mathrm{E} / V^{\prime} \mathrm{CO}_{2}$ is also highlighted and $V^{\prime} \mathrm{E} / V^{\prime} \mathrm{CO}_{2}$ slope is included in the risk assessment of $\mathrm{PAH}$ patients with cut-off values based on expert opinion (table 1).

\section{Physiology of exercise in PAH}

The origin of exercise intolerance and the occurrence of dyspnoea in PAH patients may be attributable to several pathophysiological mechanisms [20]. First, during exercise, CO should rise to meet the increased demand for oxygen by peripheral muscles. However, in patients with pulmonary vascular disease, $\mathrm{CO}$ fails to increase during exercise due to a further rise in mean pulmonary arterial pressure (mPAP) and RV failure, with consequent inadequate tissue oxygen delivery and thus the generation of early lactic acidosis $[15,21,22]$. In a recent pilot study on invasive exercise haemodynamics, LADOR et al. [23] reported the CO kinetics at the onset of exercise in PAH patients. The cardiac adaptation to exercise appeared to be slower in $\mathrm{PAH}$ patients than in controls, with a decrease in $\mathrm{CO}$ at the onset of exercise due to a transitory decrease in stroke volume, probably related to increased venous return and consequent worsening RV function. Moreover, during effort, no significant increase in stroke volume was observed, indicating that the increase in CO during exercise was attributable to the increase in HR. In the setting of CO assessment in $\mathrm{PH}$, both pre-capillary and post-capillary, FARINA et al. [24] reported an overall agreement among CO determination by thermodilution, the direct Fick method and the inert gas rebreathing technique (Innocor Rebreathing System, Innovision A/S, Odense, Denmark) in patients with $\mathrm{PH}$ without significant arterial hypoxaemia, suggesting the possibility of a noninvasive and better-tolerated haemodynamic follow-up in these patients. Unfortunately, reliable data on noninvasive assessment of exercise CO are presently lacking.

Secondly, abnormalities in arterial blood gases also play a role in exercise intolerance. In PAH, mild-to-moderate arterial hypoxaemia and arterial hypocapnia are due to a combination of low mixed venous oxygen saturation, high physiologic dead space, low alveolar-arterial diffusion and right-to-left shunt through either a patent foramen ovale or intrapulmonary shunt. Hypoxaemia exacerbates the early occurrence of lactic acidosis and stimulates the carotid bodies to augment the ventilatory drive, contributing to an excessive increase in $V^{\prime} \mathrm{E}$ during exercise [25]. In any case, the increased ventilatory response to physical activity is associated with a reduced perfusion of well-ventilated alveoli. This ventilation-perfusion mismatch causes high physiologic dead space $(V D)$ to tidal volume $(V T)$ ratio, or inefficient ventilation, reflected in a high $V^{\prime} \mathrm{E} / V^{\prime} \mathrm{CO}_{2}$ ratio measurable both as $V^{\prime} \mathrm{E} / V^{\prime} \mathrm{CO}_{2}$ at a given exercise level or as the slope of the $V^{\prime} \mathrm{E} / V^{\prime} \mathrm{CO}_{2}$ relationship [26]. The two possible behaviours of the $V^{\prime} \mathrm{E} / V^{\prime} \mathrm{CO}_{2}$ relationship are reported in figure 1 . In figure 1a, hyperventilation did not influence the physiological domains of $V^{\prime} \mathrm{E}$ during exercise and these are thus maintained such that the characteristic slopes of the $V^{\prime} \mathrm{E}$ versus $V^{\prime} \mathrm{CO}_{2}$ relationship can be appreciated. In figure $1 \mathrm{~b}$, the ventilatory stimuli are so strong as to overwhelm normal physiology, such that a single slope characterises the $V^{\prime} \mathrm{E} / V^{\prime} \mathrm{CO}_{2}$ relationship. The increase in $V^{\prime} \mathrm{E} / V^{\prime} \mathrm{CO}_{2}$ slope is paralleled by an increase in dead space ventilation during exercise. This is approximately one third of $V^{\prime} \mathrm{E}$, a value much higher when compared to healthy subjects, in whom dead space $V^{\prime} \mathrm{E}$ physiologically declines during exercise $[27,28]$. The increase of functional $V \mathrm{D} / V_{\mathrm{T}}$ and of ventilation also leads to a reduction of $\mathrm{PETCO}_{2}$ at rest and to a further decrease during exercise. Low $P \mathrm{ETCO}_{2}$ is related to ventilatory inefficiency, which causes the dilution of $P \mathrm{ETCO}_{2}$ relative to $P \mathrm{aCO}_{2}$. Furthermore, $\mathrm{PETCO}_{2}$ reduction is proportional to peak $V^{\prime} \mathrm{O}_{2}$ impairment and inversely correlated with the elevation in mPAP [29]. The arterial to end-tidal carbon dioxide tension difference $\left(\mathrm{Pa}_{\mathrm{a}} \mathrm{ETCO}_{2}\right)$, a reflection of ventilation-perfusion inequality, is positive at rest and increases in patients with $\mathrm{PAH}$, whereas, in healthy people, $\mathrm{Pa}_{\mathrm{a}} \mathrm{ETCO}_{2}$ is reduced and often negative at peak exercise [30]. Another feature is the dynamic hyperinflation observed in $60 \%$ of $\mathrm{PH}$ patients studied by LavenEziana et al. [31]. This paper is

TABLE 1 Cardiopulmonary exercise test (CPET) determinants of prognosis in risk assessment

\begin{tabular}{lccc} 
CPET parameters & Low Risk $(<5 \%)$ & Intermediate risk (5-10\%) & High risk $(>10 \%)$ \\
\hline Peak $V^{\prime} \mathbf{0}_{2} \mathrm{~mL} \cdot \mathbf{k g}^{-1} \cdot \mathrm{min}^{-1}$ & $>15$ & $11-15$ & $<11$ \\
Peak $V^{\prime} \mathbf{O}_{2} \%$ predicted & $>65$ & $65-35$ & $<35$ \\
$V^{\prime} \mathrm{E} / \mathrm{V}^{\prime} \mathrm{CO}_{2}$ slope & $<36$ & $36-45$ & $>45$
\end{tabular}

$V^{\prime} \mathrm{O}_{2}$ : oxygen uptake; $V^{\prime} \mathrm{E}$ : minute ventilation; $V^{\prime} \mathrm{CO}_{2}$ : carbon dioxide production; $V^{\prime} \mathrm{E} / \mathrm{V}^{\prime} \mathrm{CO}_{2}$ slope: slope of the relationship between $V^{\prime} E$ and $V^{\prime} \mathrm{CO}_{2}$. 

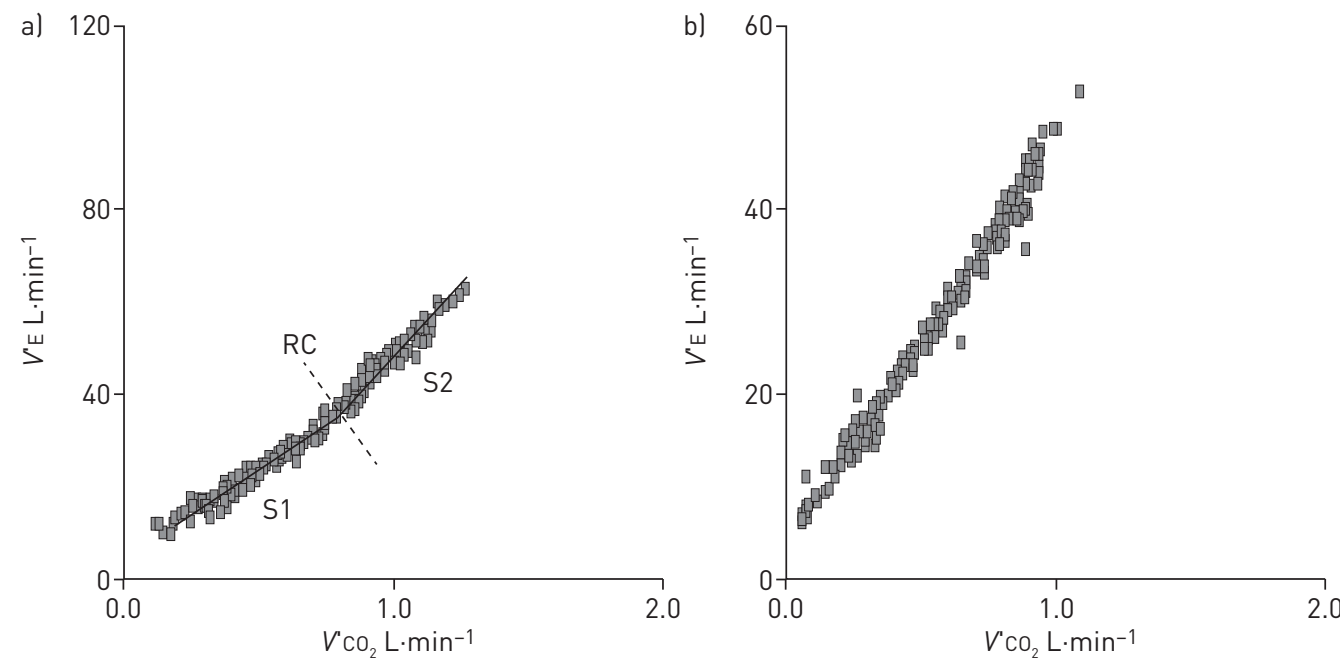

FIGURE 1 The minute ventilation $\left(V^{\prime} E\right)$ /carbon dioxide production $\left(V^{\prime} \mathrm{CO}_{2}\right)$ relationship slope in two pulmonary arterial hypertension patients. In (a) the physiological behaviour of ventilation during exercise is preserved in spite of hyperventilation, such that two slopes can be recognised around the respiratory compensation (RC) point (slope 1 (S1)=40.4 and slope $2(\mathrm{~S} 2)=55.1$ ). In (b) a single slope characterises the $V^{\prime} E / V^{\prime} \mathrm{CO}_{2}$ relationship.

interesting not only because of the $\mathrm{Pa}_{\mathrm{aTCO}}$ concept but also because of the respiratory mechanic abnormalities assessment by inspiratory capacity manoeuvres. In this respect, the visual inspection of the $V^{\prime} \mathrm{E} / V^{\prime} \mathrm{CO}_{2}$ relationship gives a lot of information (figure 2). Indeed, the slope is high and the $V^{\prime} \mathrm{E}$-axis intercept (i.e. when $V^{\prime} \mathrm{CO}_{2}=0$ ) is often close to zero or negative. This means that dead space $V^{\prime} \mathrm{E}$ increases progressively during exercise. Notably, when two linear segments are identified on the $V^{\prime} \mathrm{E} / V^{\prime} \mathrm{CO}_{2}$ relationship plot, the second has a very high slope and a severely negative $V^{\prime} \mathrm{E}$-axis intercept, showing that the increase of dead space $V^{\prime} E$ pertains specifically to the last part of exercise.

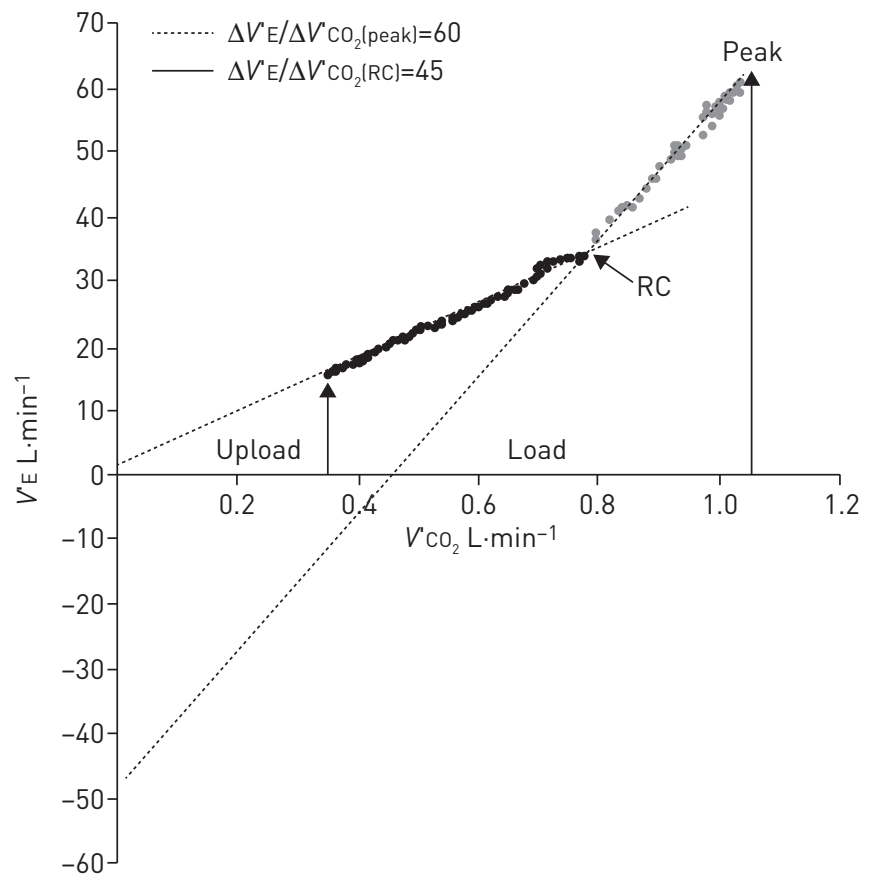

FIGURE 2 The minute ventilation $\left(V^{\prime} E\right) /$ carbon dioxide production $\left(V^{\prime} \mathrm{CO}_{2}\right)$ relationship slope in a patient with pulmonary arterial hypertension and preserved physiological behaviour of the $V^{\prime} E / V^{\prime} \mathrm{CO}_{2}$ relationship during exercise. In the first part of exercise, the $V^{\prime} \mathrm{E} / V^{\prime} \mathrm{CO}_{2}$ slope is high and the $V^{\prime} \mathrm{E}$-axis intercept is close to zero. This means that dead space ventilation progressively increases during exercise. After the end of isocapnic buffering, i.e. at the respiratory compensation (RC) point, the slope becomes steeper and the $V^{\prime} E$-axis intercept becomes severely negative showing that dead space ventilation severely increases toward the end of exercise. Reproduced from [32] with permission. 
Thirdly, an increase in chemosensitivity could also play a role in PAH hyperventilation. Indeed, severe $\mathrm{PAH}$ leads to RV failure and consequently to low $\mathrm{CO}$, which could activate a sympathetic response similar to that described in left-ventricular failure. Additionally, the further augmentation of catecholamines, arterial potassium level elevation, progressive lactacidemia, enhanced RV distension, higher pulmonary intra-vascular pressures, hypoxaemia and increased oscillations in $\mathrm{pH}$ may also contribute to increased chemoreflex activity during exercise [33]. Indeed, only very recently FARINA et al. [28] demonstrated an increase in chemosensitivity for oxygen and carbon dioxide. Specifically, the central carbon dioxide chemoreceptor presented a direct correlation with alveolar $V^{\prime} \mathrm{E}$, suggesting a preserved role for central chemoreceptor activity and alveolar $V^{\prime} \mathrm{E}$ increase during exercise. Notably, functional hypercapnic chemosensitivity is predominantly mediated by the central chemoreceptors, while peripheral hypercapnic chemosensitivity accounts for only one tenth of the overall carbon dioxide chemosensitivity [34]. However, the mechanisms which cause altered chemosensitivity are unclear. Indeed, besides the traditionally recognised stimuli such as low partial pressure of oxygen $\left(\mathrm{PO}_{2}\right)$, high partial pressure of carbon dioxide $\left(\mathrm{PCO}_{2}\right)$ and unbuffered acidosis, a direct role for lactic acid on peripheral chemoreflex activity and chemoreflex stimulation has been suggested $[35,36]$.

Finally, respiratory and peripheral muscle impairment and fatigue could also contribute to exercise intolerance. Peripheral muscle dysfunction in PAH is related to low $\mathrm{CO}$, vasoconstriction and deconditioning, but it may also be due to altered skeletal muscle microcirculation [37]. LAVENEZIANA et al. [31] showed that $\mathrm{PAH}$ patients have preserved inspiratory muscle function regardless of changes in dynamic inspiratory capacity during cycle exercise and that the inspiratory capacity manoeuvre is reliable in evaluating dynamic hyperinflation during CPET in PAH. Metabo-reflexes likely contribute to exercise-induced hyperventilation in $\mathrm{PAH}$, as is the case in patients with left-heart failure [38]; however, this has only very recently been shown in PAH [24].

\section{The use of the CPET in the diagnosis of PAH}

CPET is useful to support the diagnosis of PAH both in patients with dyspnoea of unknown aetiology and in patients with symptoms, signs, history and echocardiographic findings suggestive of $\mathrm{PH}$, allowing the identification of typical cardiac and ventilatory patterns during exercise. Moreover, in the diagnostic process, CPET is suitable for establishing and guiding therapeutic management $[19,39]$ and it has recently been demonstrated to be predictive of haemodynamic findings [40]. The CPET parameters associated with $\mathrm{PAH}$ are reported in table 2.

CPET parameters become progressively more impaired as pulmonary pressure increases and PAH worsens from mild to severe [41]. In a retrospective analysis of 53 patients, Sun et al. [20] described the exercise pathophysiology of $\mathrm{PAH}$, showing that the typical CPET pattern is characterised by a moderate to severe reduction in peak $V^{\prime} \mathrm{O}_{2}$ and work rate (WR), accompanied by a cardiovascular impairment, a respiratory impairment and a pulmonary vascular impairment. In fact, in these patients, a reduction of oxygen pulse, AT and the $V^{\prime} \mathrm{O}_{2} / \mathrm{WR}$ relationship, as well as a marked increase of the $V^{\prime} \mathrm{E} / V^{\prime} \mathrm{CO}_{2}$ slope and of the $V \mathrm{D} / V_{\mathrm{T}}$ ratio are commonly observed (table 3). For this last setting in particular, blood gas analysis should be performed during exercise to allow an accurate assessment of oxygen saturation and correct calculation of $V \mathrm{D} / V \mathrm{~T}$. In fact, the noninvasive estimation of $\mathrm{PaCO}_{2}$ (and hence of $V \mathrm{D} / V \mathrm{~T}$ ) from $P \mathrm{ETCO}$, using the equations from Jones et al. [30], does not work in patients with PAH. Thus, real blood gas measurements

TABLE 2 Common cardiopulmonary exercise test findings in patients with pulmonary arterial hypertension

\section{Reduced parameters}

Peak $\mathrm{V}^{\prime} \mathrm{O}_{2}$

WR

$\mathrm{O}_{2}$ pulse

$V^{\prime} \mathrm{O}_{2} / \mathrm{WR}$

$\mathrm{PETCO}_{2}$ at rest

$\mathrm{PETCO}_{2}$ at AT

$\mathrm{O}_{2}$ saturation during exercise

(drop >3\% without $\mathrm{PaCO}_{2}$ rise)

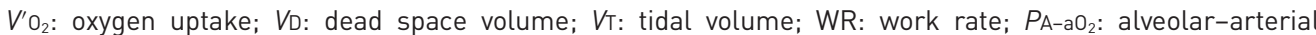
oxygen tension difference; $\mathrm{PETCO}_{2}$ : end-tidal carbon dioxide tension; AT: anaerobic threshold; $P_{a C O}$ : arterial carbon dioxide tension. 
TABLE 3 Resting and exercise values in normal subjects and primary pulmonary hypertension (PPH) patients categorised according to severity of reduction in cardiopulmonary exercise test (CPET) aerobic capacity

\begin{tabular}{|c|c|c|c|c|c|}
\hline Values & $\begin{array}{c}\text { Normal }^{\#} \\
(n=20)\end{array}$ & $\begin{array}{c}\text { Mild PPH } \\
\quad(n=3)\end{array}$ & $\begin{array}{l}\text { Moderate PPH } \\
\quad(n=14)\end{array}$ & $\begin{array}{c}\text { Severe PPH } \\
(n=22)\end{array}$ & $\begin{array}{l}\text { Very Severe } \\
\text { PPH }(n=14)\end{array}$ \\
\hline Peak $V^{\prime} \mathrm{O}_{2} \%$ predicted range & $82-132$ & $65-79$ & $50-64$ & $35-49$ & $<35$ \\
\hline Peak $V^{\prime} \mathrm{O}_{2} \%$ predicted & $101 \pm 19$ & $70 \pm 4$ & $58 \pm 4$ & $42 \pm 5$ & $27 \pm 4$ \\
\hline Peak $V^{\prime} 0_{2} \mathrm{~mL} \cdot \mathrm{min}^{-1} \cdot \mathrm{kg}^{-1}$ & $29.5 \pm 6.6$ & $14.5 \pm 3.3$ & $12.5 \pm 2.2$ & $11.2 \pm 2.6$ & $8.1 \pm 1.7$ \\
\hline AT $\%$ predicted & $104 \pm 16$ & $85 \pm 7$ & $75 \pm 10$ & $57 \pm 9$ & $41 \pm 7$ \\
\hline AT $\mathrm{mL} \cdot \mathrm{min}^{-1} \cdot \mathrm{kg}^{-1}$ & $16.3 \pm 3.9$ & $10.4 \pm 2.3$ & $9.7 \pm 1.3$ & $8.7 \pm 2.2$ & $6.8 \pm 1.3$ \\
\hline Peak $\mathrm{O}_{2}$ pulse $\%$ predicted & $108 \pm 25$ & $86 \pm 11$ & $73 \pm 8$ & $56 \pm 11$ & $39 \pm 5$ \\
\hline Peak HR \% predicted & $96 \pm 13$ & $83 \pm 12$ & $80 \pm 8$ & $77 \pm 12$ & $70 \pm 13$ \\
\hline$\Delta V^{\prime} 0_{2} / \Delta W R \mathrm{~mL} \cdot \min ^{-1} \cdot \mathrm{W}^{-1}$ & $9.6 \pm 0.9$ & $8.3 \pm 0.5$ & $7.0 \pm 1.5$ & $6.0 \pm 1.0$ & $5.6 \pm 1.3$ \\
\hline$V^{\prime} \mathrm{E} / V^{\prime} \mathrm{CO}_{2}$ at $\mathrm{AT} \%$ predicted & $99 \pm 12$ & $142 \pm 22$ & $149 \pm 21$ & $161 \pm 25$ & $219 \pm 76$ \\
\hline$V^{\prime} \mathrm{E} / V^{\prime} \mathrm{CO}_{2}$ at AT absolute & $29 \pm 4$ & $43 \pm 6$ & $45 \pm 7$ & $46 \pm 8$ & $62 \pm 20$ \\
\hline$V^{\prime} \mathrm{E} / V^{\prime} \mathrm{CO}_{2}$ slope $\%$ predicted & $88 \pm 11$ & $164 \pm 49$ & $148 \pm 27$ & $141 \pm 32$ & $215 \pm 123$ \\
\hline$V^{\prime} \mathrm{E} / V^{\prime} \mathrm{CO}_{2}$ slope absolute & $25 \pm 3$ & $49 \pm 14$ & $45 \pm 9$ & $40 \pm 10$ & $60 \pm 32$ \\
\hline Peak V'E \% MVV & $70 \pm 15$ & $63 \pm 19$ & $54 \pm 9$ & $47 \pm 11$ & $43 \pm 16$ \\
\hline MRT s & $12 \pm 10$ & $34 \pm 9$ & $37 \pm 14$ & $47 \pm 13$ & $64 \pm 15$ \\
\hline mPAP mmHg & & $48 \pm 17$ & $63 \pm 14$ & $70 \pm 18$ & $57 \pm 17$ \\
\hline $\mathrm{CO} L \min ^{-1}$ & & $5.1 \pm 1.1$ & $4.4 \pm 1.4$ & $3.5 \pm 1.0$ & $3.8 \pm 1.2$ \\
\hline PVR $\mathrm{mmHg} \cdot \mathrm{L}^{-1} \cdot \mathrm{min}^{-1}$ & & $8 \pm 4$ & $15 \pm 8$ & $18 \pm 5$ & $14 \pm 6$ \\
\hline NYHA symptom class & & $2.0 \pm 0.4$ & $2.5 \pm 0.5$ & $2.8 \pm 0.6$ & $3.3 \pm 0.4$ \\
\hline
\end{tabular}

$\mathrm{V}^{\prime} \mathrm{O}_{2}$ : oxygen uptake; AT: anaerobic threshold; HR: heart rate; WR: work rate; $V^{\prime} \mathrm{E}$ : minute ventilation; $V^{\prime} \mathrm{CO}_{2}$ : carbon dioxide production; MVV: maximum voluntary ventilation; MRT: mean response time of $V^{\prime} \mathrm{O}_{2}$ during unloaded cycling; mPAP: mean pulmonary arterial pressure; CO: cardiac output; PVR: pulmonary vascular resistance; NYHA: New York Heart Association; $V^{\prime} E / V^{\prime} \mathrm{CO}_{2}$ slope: slope of the relationship between $V^{\prime} E$ and $V^{\prime} \mathrm{CO}_{2} ; V^{\prime} \mathrm{E} / V^{\prime} \mathrm{CO}_{2}$ at $\mathrm{AT}$ : ratio of ventilation to carbon dioxide output at $A T ; \Delta V^{\prime} \mathrm{O}_{2} / \Delta W R$ : increase in oxygen uptake per increase in work rate. \#: each CPET parameter is significantly different for all PPH patients compared to that of normal control subjects $(p<0.001)$. Data is reproduced from [20] with permission.

at exercise are necessary to calculate $V \mathrm{D} / V \mathrm{~T}$ [42]. A $V \mathrm{D} / V \mathrm{~T}$ increase of $>30 \%$ during exercise indicates the presence of pulmonary vascular limitation and is associated with an increase in alveolar-arterial gradient (to $45 \mathrm{mmHg}$ or more) caused by $V^{\prime} \mathrm{E} /$ perfusion mismatch and by low alveolar-capillary gas diffusion. In a different fashion to heart failure there are multiple causes of oxygen pulse reduction in PAH. Indeed, besides a low stroke volume, a low arterial-venous oxygen difference (due to hypoxia-related low arterial oxygen content) also plays a major role. However, inert gas studies suggest that hypoxaemia during exercise in $\mathrm{PAH}$ is explained by low mixed venous oxygen and high mean $V^{\prime}$ E/perfusion even without impaired gas diffusion [43].

Peak $V^{\prime} \mathrm{O}_{2}$ describes the presence of a functional impairment and its absolute or \% predicted value is used to grade the severity of exercise limitation in patients affected by cardiac diseases. Peak $V^{\prime} \mathrm{O}_{2}$ correlates well with NYHA class in PAH patients. The kinetics of $V^{\prime} \mathrm{O}_{2}$ increase during unloaded cycling exercise are impaired in this population, as demonstrated by an increase in mean response time (MRT), indicating a less efficient coupling of oxygen delivery and uptake [20]. Low peak $V^{\prime} \mathrm{O}_{2}$ alone is not sufficient to suggest the diagnosis of PAH; however, the combination of an increase in $V^{\prime} \mathrm{E} / V^{\prime} \mathrm{CO}_{2}$ slope with reduced values of $\mathrm{PETCO}_{2}$ has high diagnostic accuracy, identifying the likelihood of pulmonary vasculopathy in patients with exertional dyspnoea of unknown origin and in those with echocardiographic findings of suspected PAH (as demonstrated by the groups of WASSERMAN and PALANGE using a cycle ergometer and a treadmill, respectively [20, 26]). YASUNOBU et al. [29] have described specific $\mathrm{PETCO}_{2}$ kinetics (in $52 \mathrm{PAH}$ patients) with reduced $\mathrm{PETCO}_{2}$ at rest, a further decrease during exercise up to the peak and abnormally low $P \mathrm{ETCO}_{2}$ values in any given exercise phase. Moreover, the authors demonstrated that the combined analysis of $\mathrm{PETCO}_{2}$ and $V^{\prime} \mathrm{E} / V^{\prime} \mathrm{CO}_{2}$ ratio at AT can classify the suspicion of PAH in unlikely, suspect, likely, or very likely subjects and is able to guide physicians to further evaluations to confirm the diagnosis. If $P \mathrm{ETCO}_{2}$ at AT is $<30 \mathrm{mmHg}$, PAH should be considered as a possible diagnosis; however, if it is $<20 \mathrm{mmHg}$, the likelihood of PAH is even higher since these values are unusual in other clinical conditions [29]. More recently, ZHAO et al. [44] demonstrated that by combining $V^{\prime} \mathrm{E} / V^{\prime} \mathrm{CO}_{2}$ slope and AT with an echocardiographic evaluation, an increase in the diagnostic specificity for PAH can be reached. In this study, 88 patients with a Doppler-estimated systolic PAP of $37-50 \mathrm{mmHg}$ by echocardiography (or $<36 \mathrm{mmHg}$ in the presence of additional echocardiographic variables suggestive of $\mathrm{PAH}$ ) were evaluated 
retrospectively. Compared to non-PAH patients, $\mathrm{PAH}$ subjects showed lower peak $V^{\prime} \mathrm{O}_{2}$ and anticipated AT, higher $V^{\prime} \mathrm{E} / V^{\prime} \mathrm{CO}_{2}$ slope and lower $P \mathrm{ETCO}_{2}$ values. Moreover, they found that the combination of $V^{\prime} \mathrm{E} / V$ ${ }^{\prime} \mathrm{CO}_{2}$ slope and AT led to a specificity of $95 \%$ and a sensitivity of $92.6 \%$ for the identification of PAH.

In addition to these parameters, $\mathrm{PAH}$ patients usually experience a decrease in oxygen saturation from rest to peak exercise of $>3 \%$ without a rise in $\mathrm{PaCO}_{2}$, which has been recognised for many years as a major criterion of pulmonary vascular exercise limitation [45]. This behaviour is commonly found in subjects with moderate, severe and very severe impaired $\mathrm{PAH}$, and this reduction is proportional to the severity of the disease. The presence of desaturation is also related to the opening of a right-to-left exercise-induced shunt. PAH patients with shunt show the lowest values of $\mathrm{PETCO}_{2}$ at rest. In this regard, it is of note that when an abrupt decrease of $\mathrm{PETCO}_{2}$ and an abrupt increase of end-tidal oxygen tension $\left(\mathrm{EETO}_{2}\right), V^{\prime} \mathrm{E} / V^{\prime} \mathrm{O}_{2}$ and respiratory exchange ratio are observed during exercise, followed by a reduction in oxygen saturation, the beginning of a right-to-left shunt possibly due to the opening of a patent foramen ovale must be suspected [46].

Regarding emerging CPET variables, PAH patients exhibit low values of the oxygen uptake efficiency (OUE) plateau (calculated as the $90 \mathrm{~s}$ average of the highest consecutive measurements of $V^{\prime} \mathrm{O}_{2} / V^{\prime} \mathrm{E}$ near $\mathrm{AT}$ ) and the OUE slope (calculated as the regression slope "a" in $V^{\prime} \mathrm{O}_{2}=\mathrm{a} \times \log _{10} V^{\prime} \mathrm{E}+\mathrm{b}$ ), indicating ventilatory inefficiency during exercise [47] (figure 3). TAN et al. [48] compared 32 patients with idiopathic PAH to 16 controls and showed that OUE slope and OUE plateau were significantly lower and the $V^{\prime} \mathrm{E} / V$ ${ }^{\prime} \mathrm{CO}_{2}$ slope was significantly higher in the former. Similarly, the study by ZHAO et al. [44] mentioned above showed a reduction of OUE slope and OUE plateau in patients with a suspicion of $\mathrm{PH}$ that accompanies the already mentioned typical CPET pattern observed in this population. These parameters are promising variables in the diagnostic management of PAH patients; however, more data are needed to confirm these initial findings.

\section{The use of the CPET for prognostication in PAH}

Right-heart catheterisation remains the gold standard to confirm a diagnosis of PAH. Some CPET parameters can predict or sometimes confirm the vascular disease pattern but they cannot confirm a diagnosis of PAH. In fact, CPET sometimes provides an indication for right-heart catheterisation. However, CPET can provide important prognostic information regarding patients with pulmonary diseases [26]. Exercise variables, such as peak $V^{\prime} \mathrm{O}_{2}, V^{\prime} \mathrm{E} / V^{\prime} \mathrm{CO}_{2}$ and arterial oxygen saturation $\left(\mathrm{SaO}_{2}\right)$ are able to better predict prognosis than resting lung function measurements. A number of CPET variables have been shown to be consistently altered in patients with $\mathrm{PAH}$ and they play a role in prognostic stratification in both $\mathrm{PAH}$ and chronic thromboembolic pulmonary hypertension (CTEPH) [49]. However, although most of these variables provide prognostic information, peak $V^{\prime} \mathrm{O}_{2}$ is most widely used for therapeutic decision making $[18,41,50,51]$.

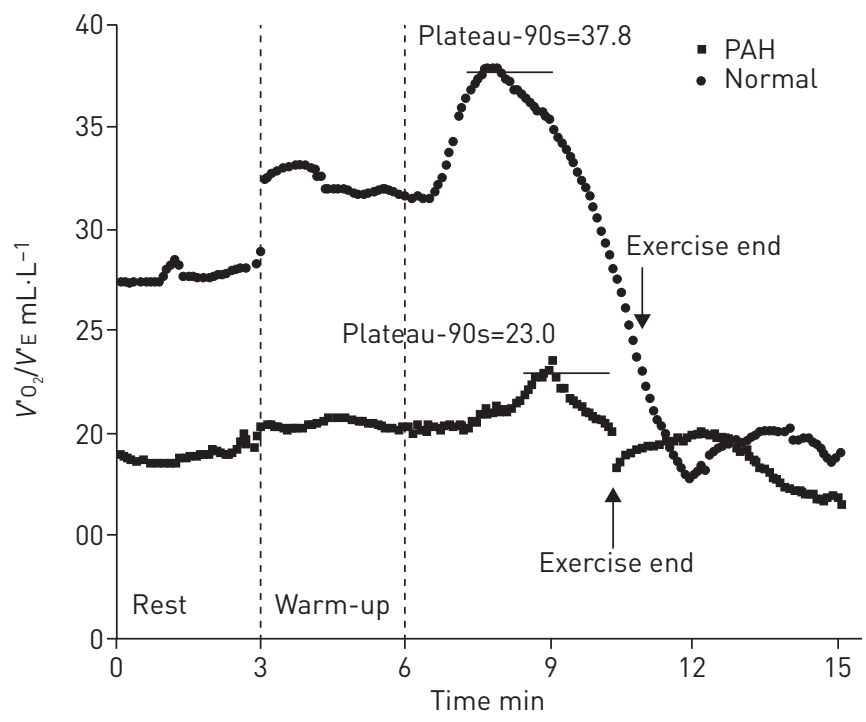

FIGURE 3 Difference of oxygen uptake efficiency (OUE; oxygen uptake $\left(V^{\prime} \mathrm{O}_{2}\right) /$ minute ventilation $\left.\left(V^{\prime} E\right)\right)$ plateau between a typical pulmonary arterial hypertension (PAH) patient and a "normal" control subject. In normal subjects, OUE typically increases during exercise from rest to plateau and then gradually decreases until the end of exercise. It then further decreases in the immediate recovery period and begins stabilising after about 2 min. In PAH patients, OUE changes in a similar way to control subjects but is always lower than in controls in the transition from rest to the end of exercise. Reproduced from [48] with permission. 
It should be noticed that, although treatment advances in the last two decades have improved symptoms and survival of patients with $\mathrm{PAH}$, prognosis remains poor and individual risk stratification is still of major importance. Therefore, it is mandatory to establish the appropriate treatment strategy and a mild approach with oral drugs or a more aggressive approach including parenteral prostanoids are both considered in international guidelines based on risk assessment [19]. However, how to translate into clinical practice the multiparametric approach to risk stratification proposed by current guidelines is still unclear. Further studies on PAH are needed to allow for a more comprehensive, definite and documented integration of CPET into the guidelines list of "variables to consider for severity assessment", which, at present, only mentions expert opinion values for peak $V^{\prime} \mathrm{O}_{2}$ and $V^{\prime} \mathrm{E} / V^{\prime} \mathrm{CO}_{2}$ [19]. Indeed, more robust prognostic evidence for peak $V^{\prime} \mathrm{O}_{2}$ and $V^{\prime} \mathrm{E} / V^{\prime} \mathrm{CO}_{2}$ arises from the studies by Wensel et al. [50] and Dевоеск et al. [52], both powered for multivariate analysis in a modern treatment context, although the added value of CPET on top of common clinical and haemodynamic variables remains unexplored. Recently, however, BADAGLiACCA et al. [53] documented the increased power of a risk prediction model considering oxygen pulse and echocardiographically-determined RV systolic function compared to the traditional model including clinical, invasive haemodynamic and 6MWT variables. Indeed, a combination of low RV fractional area change and low oxygen pulse might identify patients at a particularly high risk of clinical deterioration.

The 6MWT is the most used test to predict survival in PAH patients and, in order to assess whether CPET adds prognostic value to the information derived from 6MWT, it has been demonstrated that CPET parameters predict survival in PAH patients and add information to the prognostic value of 6MWT [54]. For example, after multivariable Cox regression, reduction in $\mathrm{SaO}_{2}$ during exercise significantly improved the univariate 6MWT prediction model. SchWAibLMAIR et al. [49] determined ventilatory efficiency in PAH and chronic thromboembolic PAH patients through CPET, identifying PAH patients with increased risk of death within 24 months from evaluation. The authors showed significant differences between survivors and non-survivors in ventilatory equivalents for oxygen $(42.1 \pm 2.1$ versus $56.9 \pm 2.6 ; \mathrm{p}<0.005)$ and for carbon dioxide (47.5 \pm 2.2 versus $64.4 \pm 2.3 ; \mathrm{p}<0.005$ ). Patients with peak oxygen uptake $\leqslant 10.4 \mathrm{~mL} \cdot \mathrm{min}^{-1} \cdot \mathrm{kg}^{-1} \mathrm{had}$ a 1.5 -fold higher risk of mortality in the following 24 months. The risk was 7.8 -fold higher with a $V^{\prime} \mathrm{E} / V^{\prime} \mathrm{CO}_{2}$ ratio at $\mathrm{AT} \geqslant 55,2.9$-fold higher with an alveolar-arterial oxygen difference $\geqslant 55 \mathrm{mmHg}$ and 5.8 -fold higher with a $V^{\prime} \mathrm{E} / V^{\prime} \mathrm{CO}_{2}$ slope $\geqslant 60$.

There are different considerations about the prognostic role of CPET in the treatment of PAH. Groepenhoff et al. [55] showed that survivors had a significantly greater change in peak $V^{\prime} \mathrm{O}_{2}$ than nonsurvivors and this change in aerobic capacity was significantly related to changes in right ventricular ejection fraction (RVEF). Notably, treatment-associated changes in $V^{\prime} \mathrm{O}_{2}$ and oxygen pulse predicted survival, whereas changes in $V^{\prime} \mathrm{E} / V^{\prime} \mathrm{CO}_{2}$ slope did not.

In addition, the combined use of peak $V^{\prime} \mathrm{O}_{2}$ and PVR provides accurate risk stratification underlining the important and complementary prognostic information from cardiopulmonary exercise testing and resting invasive haemodynamic data [50]. These different approaches may be complementary in the risk stratification of PAH patients and exercise haemodynamic data has been correlated with peak $V^{\prime} \mathrm{O}_{2}[56]$ to determine their prognostic significance. This has shown that exercise cardiac index correlates with peak $V$ ${ }^{\prime} \mathrm{O}_{2}$ and is the only independent predictor of peak $V^{\prime} \mathrm{O}_{2}$ on multivariate stepwise linear regression analyses. Furthermore, peak $V^{\prime} \mathrm{O}_{2}$ is the strongest predictor of survival in this analysis.

FERREIRA et al. [57] have demonstrated that, considering all data points, measurements of excessive exercise $V^{\prime}$ E might improve the usefulness of incremental CPET in the prognostic evaluation of PAH. OUE slope may also be a useful noninvasive marker of disease severity and outcome in paediatric patients [58]. Indeed, it has been demonstrated that ventilatory efficiency slope in children and young adults with a diagnosis of $\mathrm{PAH}$ and poor outcomes (nine deaths, three lung transplants) is significantly elevated compared to patients with better outcomes (51.1 versus 37.9; $\mathrm{p}<0.001)$. Moreover, the persistence or development of an exercise-induced right-to-left shunt strongly predicts death or transplantation in $\mathrm{PAH}$ patients, irrespectively of the haemodynamics and all other exercise measures including peak $V^{\prime} \mathrm{O}_{2}$ and OUE slope. Furthermore, a poorer OUE slope appears to be associated with a poor outcome in patients without a shunt. So, a persistent exercise-induced right-to-left shunt and poor ventilatory efficiency are highly predictive of poor outcomes in patients with PAH [59].

Another possible prognostic CPET-derived variable is the delayed post-exercise HR recovery (1 min) response [60], which is reportedly much lower in $\mathrm{PH}$ patients than in controls. The best cut-off for HR recovery in $1 \mathrm{~min}$ to discriminate between patients and controls is 18 beats. Patients with HR recovery ( $1 \mathrm{~min})>18$ had better NYHA scores, resting haemodynamics and 6MWT distance. On a multiple regression analysis that only considered CPET-independent variables, HR recovery $(1 \mathrm{~min}) \leqslant 18$ was the only predictor of mortality [60]. 


\section{Conclusions}

Today CPET is utilised for PH evaluation in only a few centres with expertise in the technique and there are currently very few data on the prognostic importance of treatment-induced changes in CPET variables. These preliminary results need to be confirmed in larger cohorts of patients and in a properly powered multicentric study. Furthermore, only an extensive use of CPET can confirm its role in the clinical assessment of PAH and provide a cost/effectiveness evaluation. The utility of CPET data from centres that seldom perform the technique or that are not specialised in the evaluation of $\mathrm{PAH}$ cases remains controversial.

Conflict of interest: P. Agostoni reports personal fees from Menarini, Novartis and Boeringer, and grants from Daiichi Sankyo, outside the submitted work.

\section{References}

1 Seeger W, Adir Y, Barbera JA, et al. Pulmonary hypertension in chronic lung diseases. J Am Coll Cardiol 2013; 62: D109-D116.

2 Hatano S, Strasser T, eds. Primary pulmonary hypertension: report on a WHO meeting. Geneva, World Health Organization, 1975. http://apps.who.int/iris/bitstream/handle/10665/39094/9241560444_eng.pdf;jsessionid= 4DEFB2B71BEDF5870191F1AE420B7EDF?sequence=1

3 Barst RJ, Rubin LJ, Long WA, et al. A comparison of continuous intravenous epoprostenol (prostacyclin) with conventional therapy for primary pulmonary hypertension. N Engl J Med 1996; 334: 296-301.

4 Rubin LJ, Mendoza J, Hood M, et al. Treatment of primary pulmonary hypertension with continuous intravenous prostacyclin (epoprostenol). Results of a randomized trial. Ann Intern Med 1990; 112: 485-491.

5 Rich S, ed. Executive summary from the World Symposium on Primary Pulmonary Hypertension, 1998, World Symposium on Primary Pulmonary Hypertension, 1998, September 6-10, 1998, Evian, France, cosponsored by the World Health Organization.

6 Simonneau G, Galie N, Rubin LJ, et al. Clinical classification of pulmonary hypertension. J Am Coll Cardiol 2004; 43: $5 \mathrm{~S}-12 \mathrm{~S}$.

7 Galie N, Hoeper MM, Humbert M, et al. Guidelines for the diagnosis and treatment of pulmonary hypertension Eur Heart J 2009; 30: 2493-2537.

8 Galie N, Humbert M, Vachiery JL, et al. 2015 ESC/ERS Guidelines for the diagnosis and treatment of pulmonary hypertension. Eur Respir J 2015; 46: 903-975.

9 Sitbon $\mathrm{O}$, Humbert $\mathrm{M}$, Nunes $\mathrm{H}$, et al. Long-term intravenous epoprostenol infusion in primary pulmonary hypertension: prognostic factors and survival. J Am Coll Cardiol 2002; 40: 780-788.

10 Miyamoto S, Nagaya N, Satoh T, et al. Clinical correlates and prognostic significance of six-minute walk test in patients with primary pulmonary hypertension. Comparison with cardiopulmonary exercise testing. Am J Respir Crit Care Med 2000; 161: 487-492.

11 Benza RL, Miller DP, Gomberg-Maitland M, et al. Predicting survival in pulmonary arterial hypertension: insights from the Registry to Evaluate Early and Long-Term Pulmonary Arterial Hypertension Disease Management (REVEAL). Circulation 2010; 122: 164-172.

12 Savarese G, Paolillo S, Costanzo P, et al. Do changes of 6-minute walk distance predict clinical events in patients with pulmonary arterial hypertension? A meta-analysis of 22 randomized trials. J Am Coll Cardiol 2012; 60: $1192-1201$.

13 Barst RJ, Langleben D, Frost A, et al. Sitaxsentan therapy for pulmonary arterial hypertension. Am J Respir Crit Care Med 2004; 169: 441-447.

14 Oudiz RJ, Barst RJ, Hansen JE, et al. Cardiopulmonary exercise testing and six-minute walk correlations in pulmonary arterial hypertension. Am J Cardiol 2006; 97: 123-126.

15 Weatherald J, Farina S, Bruno N, et al. Cardiopulmonary exercise testing in pulmonary hypertension. Ann Am Thorac Soc 2017; 14: S84-S92.

16 Paolillo S, Farina S, Bussotti M, et al. Exercise testing in the clinical management of patients affected by pulmonary arterial hypertension. Eur J Prev Cardiol 2012; 19: 960-971.

17 ATS Committee on Proficiency Standards for Clinical Pulmonary Function Laboratories. ATS statement: guidelines for the six-minute walk test. Am J Respir Crit Care Med 2002; 166: 111-117.

18 Wensel R, Opitz CF, Anker SD, et al. Assessment of survival in patients with primary pulmonary hypertension: importance of cardiopulmonary exercise testing. Circulation 2002; 106: 319-324.

19 Galie N, Humbert M, Vachiery JL, et al. 2015 ESC/ERS Guidelines for the diagnosis and treatment of pulmonary hypertension. Eur Heart J 2016; 37: 67-119.

20 Sun XG, Hansen JE, Oudiz RJ, et al. Exercise pathophysiology in patients with primary pulmonary hypertension. Circulation 2001; 104: 429-435.

21 Groepenhoff $\mathrm{H}$, Westerhof N, Jacobs W, et al. Exercise stroke volume and heart rate response differ in right and left heart failure. Eur J Heart Fail 2010; 12: 716-720.

22 Holverda S, Gan CT, Marcus JT, et al. Impaired stroke volume response to exercise in pulmonary arterial hypertension. J Am Coll Cardiol 2006; 47: 1732-1733.

23 Lador F, Bringard A, Bengueddache S, et al. Kinetics of cardiac output at the onset of exercise in precapillary pulmonary hypertension. Biomed Res Int 2016; 2016: 6050193.

24 Farina S, Teruzzi G, Cattadori G, et al. Noninvasive cardiac output measurement by inert gas rebreathing in suspected pulmonary hypertension. Am J Cardiol 2014; 113: 546-551.

25 Wasserman K, Hansen JE, Sue DY, et al. Principles of exercise testing and interpretation. 3rd Edn. Baltimore, Lippincott, Williams \& Wilkins, 1999.

26 Ferrazza AM, Martolini D, Valli G, et al. Cardiopulmonary exercise testing in the functional and prognostic evaluation of patients with pulmonary diseases. Respiration 2009; 77: 3-17.

27 Robertson HT. Dead space: the physiology of wasted ventilation. Eur Respir J 2015; 45: 1704-1716. 
28 Farina S, Bruno N, Agalbato C, et al. Physiological insights of exercise hyperventilation in arterial and chronic thromboembolic pulmonary hypertension. Int J Cardiol 2018; 259: 178-182.

29 Yasunobu Y, Oudiz RJ, Sun XG, et al. End-tidal $\mathrm{PCO}_{2}$ abnormality and exercise limitation in patients with primary pulmonary hypertension. Chest 2005; 127: 1637-1646.

30 Jones NL, Robertson DG, Kane JW. Difference between end-tidal and arterial $\mathrm{PCO}_{2}$ in exercise. J Appl Physiol 1979; 47: 954-960.

31 Laveneziana P, Garcia G, Joureau B, et al. Dynamic respiratory mechanics and exertional dyspnoea in pulmonary arterial hypertension. Eur Respir J 2013; 41: 578-587.

32 Agostoni $\mathrm{P}$, Farina S, Apostolo A, et al. Inside ventilatory regulation in pulmonary hypertension: several hidden data are still undiscovered. Eur J Prev Cardiol 2014; 21: 268-271.

33 Velez-Roa S, Ciarka A, Najem B, et al. Increased sympathetic nerve activity in pulmonary artery hypertension. Circulation 2004; 110: 1308-1312.

34 Dempsey JA, Smith CA. Pathophysiology of human ventilatory control. Eur Respir J 2014; 44: 495-512.

35 Parati G, Lombardi C, Castagna F, et al. Heart failure and sleep disorders. Nat Rev Cardiol 2016; 13: 389-403.

36 Chang AJ, Ortega FE, Riegler J, et al. Oxygen regulation of breathing through an olfactory receptor activated by lactate. Nature 2015; 527: 240-244.

37 Potus F, Malenfant S, Graydon C, et al. Impaired angiogenesis and peripheral muscle microcirculation loss contribute to exercise intolerance in pulmonary arterial hypertension. Am J Respir Crit Care Med 2014; 190: 318-328.

38 Ponikowski PP, Chua TP, Francis DP, et al. Muscle ergoreceptor overactivity reflects deterioration in clinical status and cardiorespiratory reflex control in chronic heart failure. Circulation 2001; 104: 2324-2330.

39 McLaughlin VV, Archer SL, Badesch DB, et al. ACCF/AHA 2009 expert consensus document on pulmonary hypertension. Circulation 2009; 119: 2250-2294.

40 Correale M, Tricarico L, Ferraretti A, et al. Cardiopulmonary exercise test predicts right heart catheterization. Eur J Clin Invest 2017; 47: e12851.

41 Arena R, Lavie CJ, Milani RV, et al. Cardiopulmonary exercise testing in patients with pulmonary arterial hypertension: an evidence-based review. J Heart Lung Transplant 2010; 29: 159-173.

42 Guazzi M, Marenzi G, Assanelli E, et al. Evaluation of the dead space/tidal volume ratio in patients with chronic congestive heart failure. J Card Fail 1995; 1: 401-408.

43 Dantzker DR, D'Alonzo GE, Bower JS, et al. Pulmonary gas exchange during exercise in patients with chronic obliterative pulmonary hypertension. Am Rev Respir Dis 1984; 130: 412-416.

44 Zhao QH, Wang L, Pudasaini B, et al. Cardiopulmonary exercise testing improves diagnostic specificity in patients with echocardiography-suspected pulmonary hypertension. Clin Cardiol 2017; 40: 95-101.

45 Agostoni P, Butler J. Cardiac evaluation. In: Murray JFE, Nadel JA, eds. Textbook of respiratory medicine. Boston, Saunders Company, 1994; pp. 943-962.

46 Sun XG, Hansen JE, Oudiz RJ, et al. Gas exchange detection of exercise-induced right-to-left shunt in patients with primary pulmonary hypertension. Circulation 2002; 105: 54-60.

47 Sun XG, Hansen JE, Stringer WW. Oxygen uptake efficiency plateau: physiology and reference values. Eur J App Physiol 2012; 112: 919-928.

48 Tan X, Yang W, Guo J, et al. Usefulness of decrease in oxygen uptake efficiency to identify gas exchange abnormality in patients with idiopathic pulmonary arterial hypertension. PloS One 2014; 9: e98889.

49 Schwaiblmair M, Faul C, von Scheidt W, et al. Ventilatory efficiency testing as prognostic value in patients with pulmonary hypertension. BMC Pulm Med 2012; 12: 23.

50 Wensel R, Francis DP, Meyer FJ, et al. Incremental prognostic value of cardiopulmonary exercise testing and resting haemodynamics in pulmonary arterial hypertension. Int J Cardiol 2013; 167: 1193-1198.

51 Diller GP, Dimopoulos K, Okonko D, et al. Exercise intolerance in adult congenital heart disease: comparative severity, correlates, and prognostic implication. Circulation 2005; 112: 828-835.

52 Deboeck G, Scoditti C, Huez S, et al. Exercise testing to predict outcome in idiopathic versus associated pulmonary arterial hypertension. Eur Respir J 2012; 40: 1410-1419.

53 Badagliacca R, Papa S, Valli G, et al. Echocardiography combined with cardiopulmonary exercise testing for the prediction of outcome in idiopathic pulmonary arterial hypertension. Chest 2016; 150: 1313-1322.

54 Groepenhoff $\mathrm{H}$, Vonk-Noordegraaf A, Boonstra A, et al. Exercise testing to estimate survival in pulmonary hypertension. Med Sci Sports Exerc 2008; 40: 1725-1732.

55 Groepenhoff H, Vonk-Noordegraaf A, van de Veerdonk MC, et al. Prognostic relevance of changes in exercise test variables in pulmonary arterial hypertension. PloS One 2013; 8: e72013.

56 Blumberg FC, Arzt M, Lange T, et al. Impact of right ventricular reserve on exercise capacity and survival in patients with pulmonary hypertension. Eur J Heart Fail 2013; 15: 771-775.

57 Ferreira EV, Ota-Arakaki JS, Ramos RP, et al. Optimizing the evaluation of excess exercise ventilation for prognosis assessment in pulmonary arterial hypertension. Eur J Prev Cardiol 2014; 21: 1409-1419.

58 Rausch CM, Taylor AL, Ross H, et al. Ventilatory efficiency slope correlates with functional capacity, outcomes, and disease severity in pediatric patients with pulmonary hypertension. Int J Cardiol 2013; 169: 445-448.

59 Oudiz RJ, Midde R, Hovenesyan A, et al. Usefulness of right-to-left shunting and poor exercise gas exchange for predicting prognosis in patients with pulmonary arterial hypertension. Am J Cardiol 2010; 105: 1186-1191.

60 Ramos RP, Arakaki JS, Barbosa P, et al. Heart rate recovery in pulmonary arterial hypertension: relationship with exercise capacity and prognosis. Am Heart J 2012; 163: 580-588. 